\title{
Sudden death in strabismus surgery under local anaesthesia: a case report
}

\author{
Mahesh Chand Meena ${ }^{1 *}$, Kuldeep Panchal ${ }^{2}$, Mukta Rani ${ }^{3}$ \\ Forensic Medicine and Toxicology, Lady Hardinge Medical College, New Delhi-110001, India
}

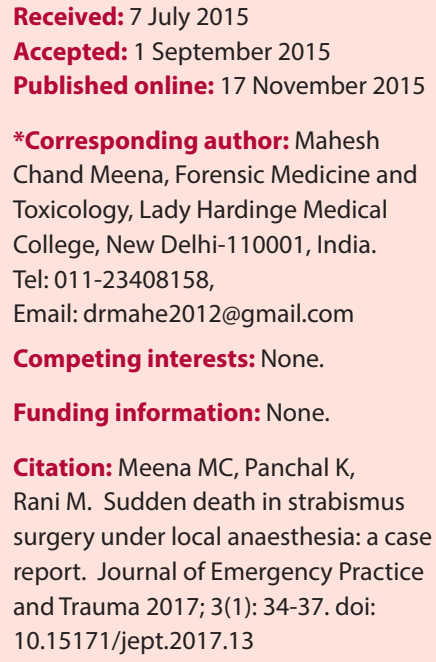

\begin{abstract}
Oculocardiac reflex (OCR) sometimes occurs as a result of pressure on the eye or traction of the intraorbital surrounding structures during ophthalmic surgery. This can result in bradycardiac arrhythmia and cardiac arrest. A 45-year-old female was undergoing an elective squint correction surgery of one eye under local anaesthesia in a private hospital in December 2013. The patient was preoperatively examined, investigated and admitted to the hospital one day prior to operation. There was no previous history of any chronic illnesses. The patient collapsed during surgery and declared dead. Doctors attempting strabismus surgery under local anaesthesia should be familiar with this phenomenon. Keywords: Local anaesthesia, Oculocardiac reflex, Cholinergic antagonists, Strabismus
\end{abstract}

\section{Introduction}

Oculocardiac reflex (OCR) or Aschner-Dagnini reflex was first discovered in 1908 (1). A number of stimuli which arise either in or near the eye such as applying traction on the internal rectus muscle or applying pressure on the eye ball can lead to slow heart rate, irregular heart beat $(2,3)$ and stoppage of heart (4-7).

The OCR is a cardiac depressor reflex. The major pathway mediating the OCR seems to consist of an afferent pathway through the ophthalmic division of fifth cranial nerve called trigeminal to the nucleus of vagus nerve and an efferent pathway through the vagus nerve to the heart $(8,9)$. There have been reports on different cases in which the OCR occurred most frequently when the medial rectus was stimulated, but the occurrence of the initiation of reflex with stimulation of the medial rectus has shown varied results among reports $(10,11)$. Such results suggest the reflex may vary in different people and for different muscles.

In general, incidence of OCR is most often seen as a complication during corrective squint surgery in children (1216). OCR is also seen during surgeries involving muscles of eye, during corrective surgery involving detached retina (17), accidental compression of gasserian ganglion (18), during enucleation of eye (19) and by wearing contact lens (20) and also during repair of nasal fracture under general anaesthesia (21). In addition, patients having gray and blue coloured iris are less prone to stimulation of this reflex than patients having brown and hazel coloured iris (22).

For prevention, prophylactic administration of anti cholinergic drugs have been advocated (3,23-25) with adequate cardiac monitoring which must accompany these interventions as emergency action may be required. OCR may be present with a decrease in heart rate, premature atrial or ventricular heart beats in pairs, ectopic heart beats, nodal rhythm, AV block and cardiac arrest.

\section{Case Report}

A 45-year-old female was undergoing elective squint correction surgery of one eye under local anaesthesia in a private hospital in December 2013. The patient was thoroughly examined in Out Patient Department, investigated for any other illnesses and admitted in hospital one day prior to surgery. There was no previous history of any chronic illnesses. Patient collapsed during surgery and declared dead on the table.

\section{Post-mortem findings}

On external examination rigor mortis was present in all four limbs of the body. Post-mortem lividity was present on the back and dependent parts of the body except contact areas in supine position. Cyanosis was present over lips and oral mucosa and nail beds of both upper limbs. 
Suture material with needle was found in situ over medial canthus of left eye left, both eyes were found congested (Figure 1). Internal examination showed hemorrhage and congestion in the left eye. All internal organs were congested. Stomach contained semi-digested food material, about $300 \mathrm{ml}$ in volume, and stomach mucosa showed no abnormality.

\section{Discussion}

Stimulation of OCR is defined as at least a $10 \%$ decrease in heart rate below baseline, which means cardiac activity must be monitored after beginning of each procedure and should be compared with the previous value, so that influences of different procedures on electrocardiac activities can be judged precisely.

It is also stated that the pressure and traction applied on the eyeball can produce a variety of cardiac manifestation which includes sinus bradycardia, ventricular ectopic beats, ventricular fibrillation and even cardiac arrest by stimulation of vagus nerve fibres in the sinus node. The prophylactic use of anticholinergic drugs may be hazardous in some patients having a history of tachycardia, hyperthyroidism, angle closure glaucoma and elderly patients with a history of coronary artery disease. In past, local anaesthesia was administered behind the eye as retrobulbar block was originally supposed to prevent the stimulation of OCR, but in later studies it was found to be one of the causative agents (26).

Case studies involving deaths during emergency surgery are more in number as compared to elective surgery, and during high risk surgery than to low risk surgery as mortality rate increases with high risk and in emergency cases. The occurrence of abnormal heart beat was quite high in the past (27). But now, due to advanced monitoring, safer anaesthetic agents and early detection of problem, the incidence of morbidity and mortality associated with this reflex has decreased significantly. Moreover the incidence of OCR is very high in patients who are not medicated with an anticholinergic drug prophylactically. Hence, all the patients undergoing general anaesthesia for eye surgeries should have a proper anticholinergic pre-medication with drugs such as atropine sulphate to decrease the incident of OCR $(28,29)$.

According to a study published by Safavi and Honarmand (30), the induction of anaesthesia with ketamine was associated with minimal chances of cardiovascular changes induced by OCR during strabismus surgery. According to a study published in 2010 by Sing et al (31) ketamine when used as a topical anaesthetist in rabbits, effectively prevented the occurrence of OCR without any local adverse effect. On the other hand, a study conducted by Baek et al (32) showed that OCR can also occur during endoscopic sinus surgery and is not limited to ocular surgeries only, and in a case reported by Stathopoulos et al (33), he showed that OCR stimulation can occur following insertion of a bilateral nasal balloon catheter for controlling bleeding in a case of head trauma.

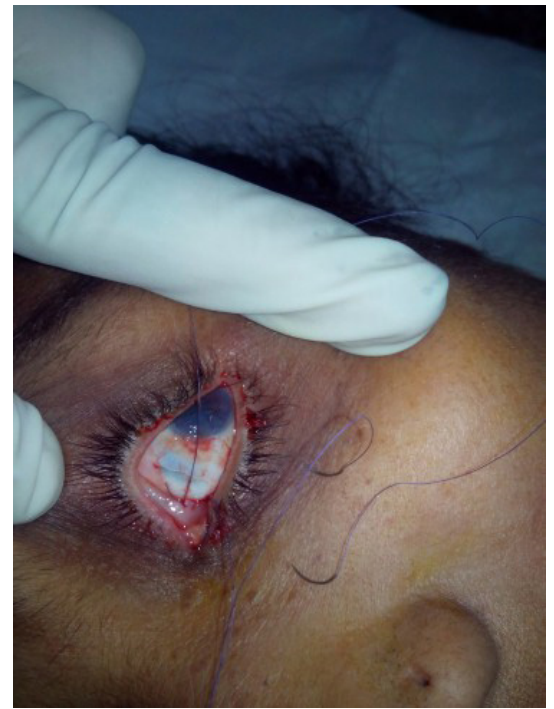

Figure 1. Suture material with needle in situ present over medial canthus of left eye left.

The incidence of dysrhythmias is not limited to squint surgeries alone, in a study done by Yang and Oh, they showed that intraocular foreign bodies can also elicit this reflex (34). Likewise diseases involving choroid can also stimulate the OCR (35). In terms of occurrence, general anaesthesia is also an important risk factor of this reflex, as in a study done by Grover et al (17) they showed that local anaesthesia produced less bradycardia and ectopic arrhythmias and accordingly they urged the use of local anaesthesia over general anaesthesia in surgeries involving extra ocular muscle manipulation. According to a study published by Tramèr et al (36), they suggested that propofol with prophylactic atropine may be used safely in adults undergoing strabismus surgery. With thiopentone, isoflurane or propofol as anaesthetic agents with or without N20, the risk of OCR and postoperative nausea and vomiting (PONV) was low and no differences were found between groups. Karhunen et al (23) compared atropine and glycopyrolate effectiveness in preventing dysrhythmias and he found atropine to be more effective as a choice for pre-medication in strabismus surgery.

Bosomworth et al (37) stated in a study that continuous monitoring of the cardiac rate and rhythm of the patient undergoing eye muscle surgery is necessary to avert any untoward incidents. The potential for fatality or cardiac arrest could be the result of ignoring preventive measures. Cardiac arrest could also be due to cardiac toxicity by inadvertent intravascular injection of local anaesthetic. Considering the above danger associated with retrobulbar block, the focus must be on a safer peribulbar block. Although peribulbar block is a safe and a superior procedure, its practice is mostly limited to experienced and skilled ophthalmologists in institutes of higher learning. There was a general feeling from our case report that a response to a death that is a surprise may well be different from one that is expected. 


\section{Conclusion}

It is important to analyze this condition so that lessons can be learned and practices can be improved particularly in case of unexpected deaths. Surgeons attempting strabismus surgery under local anaesthesia should be familiar with this dreadful phenomenon, and required preventive measures should be taken into account.

\section{Ethical issues}

We got informed consent from relatives to report.

\section{Authors' contributions}

All authors are directly involved as a board member in case report.

\section{References}

1. Myers EF. Anesthesiology. Oculcardiac reflex in Paediatric patients. Anesthesiology 1979; 51; 350-55.

2. Gandevia SC, McCloskey DI, Potter EK. Reflex bradycardia occurring in response to diving, nasopharyngeal stimulation, and ocular pressure. J Physiol 1978; 276: 383-94.

3. Hunsley JE, Bush GH, Jones CJ. A study of glycopyrolate and atropine in suppression of oculocardiac reflex during strabismus surgery in children. Br J Anaesth 1982; 54(4): 459-64.

4. Seo K, Takayama H, Araya Y, Miura K, Someya G. A case of sinus arrest caused by opening the mouth under general anesthesia. Anesth Prog 1994; 41(1): 17-8.

5. Smith RB. Death and the oculocardiac reflex. Can J Anaesth 1994; 41(8): 760.

6. Campbell R, Rodrigo D, Cheung L. Asystole and bradycardia during maxillofacial surgery. Anesth Prog 1994: 41(1): 13-6.

7. Lang SA, VanderWal M. Death from the oculocardiac reflex. Canad J Anaesth 1994; 41(2): 161.

8. Aschner B. Ueber einen bisher noch nicht beschriebenen Reflex vom Auge auf Kreislauf and Atmung: Verschwinden des Radialispulsbei Druck auf das Auge. Wien Klin Wochenschr 1908; 21: 1529.

9. Sabena V, Posteli T. Oculocardiac reflex: electrocardiographic study. Folia Cardiol 1941; 2: 301-31.

10. Welhalf WR, Johnson DC. The oculocardiac reflex during extraocular muscle surgery. Arch Ophthalmol 1965; 73: 43.

11. Apt L, Isenberg S, Gaffney WL. The oculocardiac reflex in strabismus surgery. Am J Ophthalmol 1973; 76(4): 533-6.

12. Watcha MF, Simeon RM, White PF, Stevens JL. Effect of Propofal on the incidence of post operative vomiting after strabismus surgery in paediatric outpatients. Anesthesiology 1991; 75(2): 204-9.

13. Tramer MR, Sansonett A, Fuchs-Buder T, Rifat K. Oculocardiac reflex and postoperative vomiting in paediatric strabismus surgery. A randomised controlled trial. Acta Anaesthesiol Scand 1998; 42(1):
117-23.

14. Hahnenkamp K, Honemann CW, Fischer LG, Durieux ME, Muehlendyck H, Braun U. Effect of different anaesthetic regimes on the oculocardiac reflex during paediatric strabismus surgery. Paediatr Anaesth 2000; 10(6): 601-8.

15. Allison CE, De Lange JJ, Koole FD, Zuurmond WW, Ros HH, van Schagen NT. A comparison of the incidence of the oculocardiac and oculorespiratory reflexes during sevoflurane or halothane anesthesia for strabismus surgery in children. Anesth Analg 2000; 90(2): 306-10.

16. Karanovic N, Jukic M, Carev M, Kardum G, Dogas Z. Rocuronium attenuates oculocardiac reflex during squint surgery in children anesthetized with halothane and nitrous oxide. Acta Anaesthesiol Scand 2004; 48(10): 1301-5.

17. Grover VK, Bhardwaj N, Shobana N, Grewal SP. Oculo cardiac reflex during retinal surgery using peribulbar block and nitrous oxide narcotic anaesthesia. Ophthalmic Surg Lasers 1998; 29(3): 207-12.

18. Añez C, Rodríguez-Pérez A, Morales F, Partida C. Cardiac Trigeminal reflex during compression of gasserain ganglion. Rev Esp Anestesiol Reanim 1994; 41(1): 42-3. [In Spanish]

19. Munden PM, Carter KD, Nerad JA. Oculocardiac reflex during enucleation (letter). Am J Opthalmol 1991;111(3):378-9

20. Arnold R. Oculocardiac reflex caused by contact lenses. (author reply). Ophthalmic Physiol Opt 2003; 23(6): 571-2.

21. Locke MM, Spiekermann BF, Rich GF. Trigeminovagal reflex during repair of a nasal fracture under general anesthesia. Anesth Analg 1999; 88(5): 1183-4.

22. Kwick RS. Anesthesia dysrythemias in ocular surgery. Anesthesia 1980; 33: 46.

23. Karhunen U, Cozanitis DA, Brander P. The oculocardiac reflex in adults. A dose response study of glycopyrrolate and atropine. Anaesthesia 1984; 39(6): 524-8.

24. Chisakuta AM, Mirakhur RK. Anticholinergic prophylaxis does not prevent emesis following strabismus surgery in children. Paediatr Anaesth 1995; 5(2): 97-100.

25. Arnold RW, Farah RF, Monroe G. The attenuating effect of intraglossal atropine on the oculocardiac reflex. Binocul Vis Strabismus Q 2002; 17(4): 313-8.

26. Mirakhur RK, Jones CJ, Dundee JW, Archer DB. I.m. or i.v. atropine or glycopyrrolate for the prevention of oculocardiac reflex in children undergoing squint surgery. Br J Anaesth 1982; 54(10): 1059-63.

27. Blanc VF, Hardy JF, Milot J, Jacob JL. The oculocardiac reflex: a graphic and statistical analysis in infant and children. Can Anaesth Soc J 1983; 30(4): 360-9.

28. Mirakhur RK, Shepherd WF, Jones CJ. Ventilation and the oculocardiac reflex. Prevention of oculocardiac reflex during surgery for squints: role of controlled ventilation and anticholinergic drugs. Anaesthesia 
1986; 41(8): 825-8.

29. Shah TH, Samad R, Salahuddin M, Shah SH, Mufti AJ, Rahman S, Syed H. Oculocardiac refelx in Strabismus Surgery under general anesthesia. J Med Sci (Peshawar) 2013; 21(2): 84-7.

30. Safavi MR, Honarmand A. Comparative effects of different anaesthetic regimens on the oculocardiac reflex. Iran Cardiovasc Res J 2007; 1(2); 98-102.

31. Sing J, Roy S, Mukherjee P, Konar D, Hazra S. Influence of topical anesthetics on oculocardiac reflex and corneal healing in rabbits. Int J Ophthalmol 2010; 3(1): 14-8. doi: 10.3980/j.issn.2222-3959.2010.01.04

32. Baek HI, Park BC, Kim WH, Son WS. Oculocardiac reflex during the endoscopic sinus surgery. Am J Otolaryngol 2010; 31(2): 136-8.

33. Stathopoulos P, Mezitis M, Kostakis G, Rallis G. Iatrogenic oculocardiac reflex in a patient with head injury. Cranial Maxillofacial Trauma Reconstruction
2012; 5(4): 235-38. doi: 10.1055/s-0032-1322532.

34. Yang HS, Oh DE. A case of delayed oculocardiac reflex induced by an intraorbital foreign body. Ophthal Plast Reconstr Surg 2011; 27(1): 2-4.

35. Steinmetz A, Ellenberger K, März I, Ludewig E, Oechtering G. Oculocardiac reflex in a dog caused by a choroidal melanoma with orbital extension. J Am Anim Hosp Assoc 2012; 48(1): 66-70. doi: 10.5326/ JAAHA-MS-5685

36. Tramèr MR, Fuchs-Buder $\mathrm{T}$, Sansonetti A, Rifat K. Low incidence of the oculocardiac reflex and postoperative nausea and vomiting in adults undergoing strabismus surgery. Can J Anaesth 1997; 44(8): 830-5.

37. Bosomworth PP, Ziegler CH, Jacoby J. The oculocardiac reflex in eye muscle surgery. Anesthesiology 1958; 19(1): 7-10. 